\title{
Transtorno Alimentar e Transmissão Psíquica Transgeracional em um Adolescente do Sexo Masculino
}

\author{
Élide Dezoti Valdanha-Ornellas \\ Universidade de São Paulo, SP, Brasil.
}

\author{
Manoel Antônio dos Santos \\ Universidade de São Paulo, SP, Brasil.
}

\begin{abstract}
Resumo: A anorexia nervosa (AN) é um transtorno alimentar de etiopatogenia multifatorial. Cuidados maternos e a configuração vincular mãe-filho são considerados fatores primordiais para o desenvolvimento psicoemocional e podem influenciar no aparecimento e curso do transtorno. Este estudo teve por objetivo investigar a transmissão psíquica dos cuidados em três gerações de uma família que tinha um de seus membros acometidos, buscando identificar os conteúdos transmitidos transgeracionalmente e suas possíveis relações com o desenvolvimento da AN. Foram entrevistados três membros de uma família: avó materna, mãe e filho de 15 anos com diagnóstico de AN. Os dados foram coletados por meio de roteiros de entrevista semiestruturada e analisados a partir do referencial teórico da transmissão psíquica transgeracional. Os resultados apontam uma dinâmica familiar marcada por figuras femininas dominantes e ausência de figuras masculinas com quem o adolescente pudesse se identificar. Insatisfação corporal, restrições alimentares e preocupação intensa com o corpo permeiam as três gerações estudadas, porém essas manifestações tornam-se sintomáticas na terceira geração, com o desenvolvimento do transtorno. Os dados corroboram a necessidade de incluir os familiares no tratamento para torná-los conscientes dos processos psíquicos envolvidos, permitindo que a família se reorganize emocionalmente e possa elaborar os conteúdos latentes transmitidos na cadeia intergeracional.
\end{abstract}

Palavras-chave: Anorexia Nervosa, Relações Familiares, Relações Mãe-criança, Transmissão Psíquica entre Gerações, Psicanálise do Adolescente.

\section{Eating Disorders and Transgenerational Psychic Transmission in a Male Teenager}

\begin{abstract}
Anorexia nervosa (AN) is an eating disorder (ED) of multifactorial etiopathogeny. Maternal care and mother-child link configuration are critical factors for psycho-emotional development and can influence the onset and course of this disorder. This study aimed to investigate the psychic transmission of care in three generations of a family that had one of their members affected by AN in order to identify the transgenerational transmitted contents and their possible relationship with the development of AN. Three members of a family were interviewed: maternal grandmother, mother and a male adolescent diagnosed with AN. Data were collected through semi-structured interview scripts and analyzed from the theoretical framework of transgenerational psychic transmission. Results show a family dynamic marked by imposing and dominant female figures, and absence of male figures with whom the adolescent could identify himself. Body dissatisfaction, dietary restrictions and intense preoccupation with the body permeate the three generations studied, but only became symptomatic in the third generation, with the development of the disorder. Data support the need to include family members in the treatment to make them aware of the psychic processes involved, allowing the family to reorganize emotionally and elaborate the latent contents transmitted in the intergenerational chain.

Keywords: Anorexia Nervosa, Family Relations, Mother Child Relations, Psychic Transmission between Generations, Adolescent Psychoanalysis.
\end{abstract}




\title{
Trastorno Alimentar y Transmisión Psíquica Transgeneracional en un Adolescente del sexo Masculino
}

\begin{abstract}
Resumen: La anorexia nerviosa (AN) es un trastorno de la alimentación de etiología multifactorial. Los cuidados maternos y la configuración del enlace entre madre e hijo son factores críticos para el desarrollo psicoemocional y pueden influir en la aparición y el curso de la enfermedad. Este estudio tuvo como objetivo investigar la transmisión psíquica de los cuidados en tres generaciones de una familia que tuvo a uno de sus miembros afectado por la enfermedad, tratando de identificar los contenidos transmitidos entre las generaciones y su posible relación con el desarrollo de la AN. Fueron entrevistados tres miembros de una misma familia: abuela, madre e hijo de 15 años con diagnóstico de AN. Los datos fueron recolectados a través de entrevistas semi-estructuradas y analizados a partir del marco teórico de la transmisión psíquica transgeneracional. Los resultados muestran una dinámica familiar marcada por figuras femeninas dominantes y escasez de figuras masculinas con las que el adolescente pudiera identificarse. La insatisfacción corporal, las restricciones en la dieta y la intensa preocupación por el cuerpo impregnan las tres generaciones estudiadas, pero estas manifestaciones se vuelven sintomáticas en la tercera generación, con el desarrollo de la enfermedad. Los datos apoyan la necesidad de incluir a miembros de la familia en el tratamiento para que sean conscientes de los procesos psíquicos involucrados, por lo que la familia puede reagruparse emocionalmente y elaborar los contenidos latentes de la transmisión psíquica entre las generaciones.

Palabras clave: Anorexia Nerviosa, Relaciones Familiares, Relaciones Madre-niño, Transmisión Psíquica entre las Generaciones, Psicoanálisis del Adolescente.
\end{abstract}

\section{Introdução}

O vocábulo anorexia deriva da palavra grega anorektos, que significa "sem desejo, sem apetite", e foi integrado ao vocabulário latino em 1984. Os primeiros relatos de mulheres com sintomas desse transtorno mental remontam à Idade Média, quando se acreditava que a recusa em comer seria uma forma de desenvolvimento espiritual, pois propiciaria a ascese, ou seja, a superação das necessidades físicas, então vistas como terrenas. No período medieval, sob a influência da Igreja nos costumes e modos de vida, os apetites da carne precisavam ser disciplinados por meio de jejuns prolongados. Só posteriormente o termo anorexia passou a ter um status de psicopatologia, de "doença da alma” (Fernandes, 2006).

Segundo o Manual Diagnóstico e Estatístico de Transtornos Mentais, em sua quinta revisão - DSM-V (American Psychiatric Association, 2013), a anorexia nervosa (AN) é caracterizada por comportamento alimentar gravemente perturbado, tentativa de manter excessivo controle sobre o peso corporal por meios não apropriados e acentuada distorção da imagem corporal. O paciente vivencia um medo patológico de engordar, embora seu peso esteja abaixo do ideal, resultando em caquexia, ou seja, fraqueza geral do corpo e má disposição corporal decorrente da desnutrição (Bighetti et al., 2007; Cartwright, 2004; Claudino, \& Borges, 2002; Leonidas, \& Santos, 2013; Saikali, Soubhia, Scalfaro, \& Cordás, 2004).

A literatura científica e a observação clínica sugerem que a $\mathrm{AN}$, assim como outros transtornos alimentares (TAs), tem múltiplas causas. Devido à etiopatologia multifatorial e às potenciais complicações decorrentes do transtorno, é preconizado o tratamento por equipe multidisciplinar. São considerados fatores desencadeadores e mantenedores do quadro psicopatológico: a dinâmica das relações familiares, a estrutura e funcionamento da personalidade e o meio sociocultural (Appolinário, \& Claudino, 2000; Bighetti et al., 2007; Oliveira, \& Santos, 2006; Polivy, \& Herman, 2002).

Del Priore (2000), ao considerar as mudanças ocorridas na percepção corporal entre gerações, afirma que: "Diferentemente de nossas avós, não nos preocupamos mais em salvar nossas almas, mas em salvar nossos corpos da desgraça da rejeição social. Nosso tormento não é o fogo do inferno, mas a balança 
e o espelho" (p. 11). A historiadora ressalta que o sofrimento associado ao corpo na contemporaneidade antes fora uma dor da alma. A hipervalorização do corpo magro e esguio se dá concomitantemente com a hiperinflação do corpo como objeto de consumo e de desejo (Hoogland, 2002). A preocupação obsessiva com peso e forma corporal, o culto desenfreado ao individualismo e o empobrecimento das relações interpessoais convertem o corpo em fonte inesgotável de ansiedade e frustração, à medida que os padrões ideais valorizados são inalcançáveis.

Ainda que os aspectos socioculturais que caracterizam a era contemporânea incidam em maior ou menor grau sobre todos os indivíduos, apenas uma parcela, estimada entre 1 a $4 \%$ da população, desenvolve algum tipo de transtorno do comportamento alimentar (Andrade, \& Santos, 2009). Essa prevalência, embora significativa em termos clínicos e epidemiológicos, dá margem para que se interrogue a participação de fatores específicos, além dos ditames culturais que podem estar na origem dos sintomas. Uma das apostas mais promissoras do conhecimento recente é a intersecção entre fatores individuais e familiares. Ou seja, o funcionamento da personalidade, em conexão com a dinâmica familiar, poderia explicar porque certos indivíduos parecem estar mais vulneráveis e propensos do que outros a desenvolverem um TA.

Na família contemporânea trava-se uma batalha entre o conhecido (tradicional) e o novo (moderno). Neste tensionamento entre rupturas e permanências, resta uma profunda nostalgia em relação ao "santuário perdido" da família, que pertencia a uma tradição que é, a todo o tempo, reinventada no processo de transmissão de valores, crenças e estilos de vida (Giddens, 2003). A família contemporânea se destaca pelo suposto fim ou declínio da autoridade do pai, o consequente poder ilimitado materno e a ameaça de apagamento ou extinção das diferenças entre os sexos e as gerações (Roudinesco, 2003). Mas como essas transformações e reconfigurações da organização e dinâmica familiar repercutem no curso do desenvolvimento individual? Como os fatores familiares e socioculturais incidem na formação do psiquismo de cada membro familiar? Como se dá o enlace simbólico entre o "eu" e o "nós" familiar?

Nas últimas décadas, uma concepção teórica de matriz psicanalítica tem sido desenvolvida a partir do pressuposto de que, no processo de formação da subjetividade, entrelaçam-se aspectos individuais e familiares, que prosperam largamente alicerçados na sedimentação gradual das fantasias inconscientes. Esse campo de investigações que se abre a partir dessa preocupação ficou conhecido como transmissão psíquica entre gerações. Antes, porém, de o abordarmos, é preciso esclarecer que suas raízes remontam ao pensamento freudiano.

Em sua formulação conceitual do funcionamento mental, embora tenha dado proeminência ao aparelho psíquico individual, Freud progressivamente foi se deslocando na direção de um processo que vai além da estrutura intrapsíquica, apontando para a constituição intersubjetiva do psiquismo (Gomes, \& Zanetti, 2009). De fato, ao longo de sua extensa obra, Freud formulou análises sobre dinâmicas psíquicas que incluíam claramente a dimensão grupal, reconhecendo assim as interações dos psiquismos individuais em produções interpsíquicas (Ávila, 2004), como no Caso Dora, em que os sintomas histéricos aparecem sobredeterminados pelas complexas relações familiares da paciente. Os estudos sobre as neuroses infantis, como os romances familiares do neurótico, também testemunham essa aproximação entre mente individual e grupal. Mas é no texto seminal Psicologia de grupo e análise do ego que Freud (1921/1980) melhor explicita o quanto suas descrições do aparelho psíquico pressupunham as relações do indivíduo com os demais. Nessa obra, o autor postula nitidamente a presença da intersubjetividade na constituição psíquica do sujeito. É ali que o pai da psicanálise afirma que toda Psicologia é, antes de tudo, uma Psicologia social. Desse modo, o conhecimento da vida psíquica individual não pode ser abstraído da sua dimensão de produção grupal.

Eiguer $(1985 ; 1998)$ discorre sobre os mecanismos de transmissão de conteúdos psíquicos inconscientes entre gerações e suas possíveis reverberações nas gerações ulteriores. O referencial teórico de transmissão psíquica intergeracional, que fundamenta o presente estudo, valoriza a herança psíquica e destaca os conteúdos que ficam impedidos de serem transformados e metabolizados pelo aparelho psíquico familiar. Os conteúdos psíquicos inconscientes não processados por uma geração são como "metabólitos" indigeríveis, que permanecem inacessíveis ao trabalho de metaforização e representabilidade, contribuindo para a formação de sintomas nas gerações subsequentes. 
A AN é uma organização psicopatológica que pode ser compreendida como uma manifestação extrema de conteúdos inacessíveis à representação psíquica, que são transmitidos na cadeia intergeracional sem o necessário trabalho psíquico de metabolização que conduz ao processo de significação. Em algum momento da transmissão, esses conteúdos brutos - não digeridos e, por conseguinte, não sonháveis - alcançam um ponto de saturação e vão se depositar e constelar em um determinado membro do grupo familiar. Essa pessoa, por uma condição especial de vulnerabilidade e por identificação com o sofrimento familiar que não pôde ser explicitado, nem transformado em metáfora, cai gravemente doente, com a deposição maciça de conteúdos irrepresentáveis. Seguindo-se essa linha de compreensão dos fenômenos psíquicos, o aparente não sentido dos sintomas anoréxicos seria reflexo dos buracos negros das representações psíquicas familiares.

Benghozi (2010) utiliza a metáfora do corpo "tubo" para descrever a complexidade fantasmática da pessoa com funcionamento anoréxico. A AN seria a deposição, em um determinado membro da família, de um sintoma de um corpo psíquico familiar esburacado, campo conflagrado de uma adolescência em crise, que poderia se complicar, gerando uma "adolescência-catástrofe", na qual incidem outros sintomas associados, difratados sobre os diferentes membros da família. Para este autor, o vazio do não comer seria a expressão de uma hemorragia narcísica, como se houvesse uma fuga de substância psíquica pelos dilaceramentos dos continentes esburacados, ou seja, por meio da fabricação psíquica de um corpo "tubo". Nessa chave de compreensão teórica, os graves sintomas que acometem os sujeitos anoréxicos só se tornariam inteligíveis se confrontados com a trama fantasmática tecida pelas relações familiares, tanto no sentido da configuração familiar atual como das ressonâncias dos legados intergeracionais que são transmitidos sem a devida elaboração psíquica (Valdanha, Scorsolini-Comin, \& Santos, 2013).

Formulações teóricas nesse campo ainda carecem de validação clínica, haja vista que os estudos psicanalíticos têm se desdobrado primordialmente em uma vertente teórica (Mendonça, 2015). Ao considerar essas questões, este estudo teve por objetivo investigar a transmissão psíquica dos cuidados em três gerações de uma família (avó, mãe, paciente) que tinha um de seus membros acometidos pelo trans- torno, buscando identificar os conteúdos transmitidos transgeracionalmente e suas possíveis relações com o desenvolvimento da AN na geração mais nova.

\section{Percurso metodológico}

Trata-se de um estudo do tipo exploratório, descritivo e transversal, no enfoque qualitativo de pesquisa. O desenho escolhido foi o estudo de caso, que propõe uma investigação concentrada em uma única situação, considerada privilegiada para que se possa compreender em profundidade características importantes de acontecimentos da vida real (Stake, 2000). Os dados foram analisados de acordo com o referencial teórico da transmissão psíquica transgeracional.

A partir de um corpus de pesquisa constituído por seis famílias investigadas, extraiu-se o caso da Família Miranda, elegendo-se um representante de cada geração, a saber: o paciente, sua mãe e sua avó materna. Essa escolha foi motivada pelo fato deste caso se destacar como o único em que o participante era do sexo masculino. A prevalência de TAs em homens é relativamente baixa - cerca de um caso para cada 10 mulheres diagnosticadas. Ademais, a forma de apresentação dos sintomas e a evolução do quadro parecem ser diferentes em homens acometidos, quando comparados com as mulheres (Andrade, \& Santos, 2009).

Participaram da pesquisa Júlio, sua mãe (Júlia) e a avó materna, dona Leonora. Todos os nomes próprios utilizados neste estudo são fictícios, de modo a preservar a identidade dos participantes. Por ocasião da coleta de dados, Júlio, 15 anos, estava em tratamento para AN havia dois meses e apresentava, do ponto de vista clínico, desnutrição grau 3. Além dos sintomas de AN foi diagnosticado com traços impulsivos de personalidade, Episódio Depressivo em remissão e Transtorno de Ansiedade Generalizada, também considerado remitido.

Os três participantes formalizaram sua concordância em participar da pesquisa por meio da assinatura do Termo de Consentimento Livre e Esclarecido. Para coleta de dados foram utilizados três roteiros de entrevista semiestruturada, ajustados para cada participante. Os roteiros abordaram questões relativas à infância, adolescência e demais fases do desenvolvimento de cada participante, relações familiares, cuidados com a prole, com o corpo e a alimentação. As entrevistas tiveram duração média de 50 minutos. 
A coleta dos dados com mãe e filhos foi realizada no local de tratamento, em sala reservada. Já a entrevista com a avó foi realizada em seu próprio domicílio, a pedido da participante. Os relatos foram organizados pelo método de Análise de Conteúdo na modalidade temática (Braun, \& Clarke, 2006) e analisados segundo o referencial teórico psicanalítico da transmissão psíquica transgeracional. O projeto de pesquisa foi aprovado pelo Comitê de Ética em Pesquisa da instituição universitária a qual os pesquisadores estão vinculados (Processo CEP-FFCLRP $\left.\mathrm{n}^{\circ} 567 / 2011-2011.1 .1035 .59 .5\right)$.

\section{Resultados e discussão}

Serão apresentadas as categorias extraídas e os resultados referentes a cada participante, com o intuito de evidenciar o processo de transmissão psíquica entre as diferentes gerações. Antes, contudo, será apresentado um perfil com as características psicológicas mais salientes das pessoas entrevistadas.

Dona Leonora tem 68 anos e é uma avó bem ativa. Havia completado um curso universitário e trabalhava fora de casa. Dirige um carro elegante e mora em uma casa própria. No dia da entrevista ela vestia calça jeans, blusa de algodão e camisa xadrez por cima da blusa, o que demonstra que está afinada e em compasso com a moda atual. Usava maquiagem discreta. Em um primeiro contato, a pesquisadora pôde perceber que ela era muito falante e desinibida, no que se assemelhava à sua filha, também participante da pesquisa.

Dona Leonora inicia a conversa, antes da entrevista propriamente dita, mencionando que já havia acompanhado Júlio no tratamento, no período de triagem e de elaboração do caso novo, enquanto ele ainda morava com ela. Relata que deixou de comparecer ao serviço porque considera que a presença da mãe é mais importante do que a dela, e as duas não poderiam ir juntas em razão da rotina de trabalho. Dona Leonora, na época da entrevista, estava morando em sua casa com seu neto mais jovem, irmão de Júlio. Mudara para a nova residência, construída a seu gosto, havia cerca de um ano. Preocupa-se em destacar, diversas vezes ao longo de nossa conversa, que a casa é muito bonita, porém os móveis são antigos, já que ela não teria condições financeiras de trocá-los no momento. A senhora é viúva havia dois anos. Tem três filhos. Júlia foi a primogênita, depois teve dois homens. A mãe de dona Leonora é viva, tem 93 anos e necessita de cuidados especiais devido a problemas de saúde.

Ainda na primeira etapa da entrevista, conta que nunca morou sozinha, pois sempre um dos netos estava com ela, convivendo na casa. Antes da mudança, residia no mesmo prédio que a filha Júlia, seu companheiro e seus filhos. O neto Júlio já morava com ela em seu apartamento e sempre esboçava o desejo de morar com a avó em sua casa, quando esta fosse finalizada. Atualmente, Júlio voltou para a casa da mãe e seu irmão mais novo mudou-se para a casa da avó. Dona Leonora mostra ser muito participativa na vida dos netos e da filha. Sente-se como uma segunda mãe e com liberdade de intervir na educação dos netos.

Júlia, a filha mais velha de Dona Leonora, é uma mulher que aparenta ser muito espontânea. Pareceu muito interessada e animada em colaborar com a pesquisa. Recém-chegada ao serviço para o tratamento de Júlio, ela parece encarar com tranquilidade os sintomas do filho, não obstante sua gravidade. Diferentemente de outras mães, que chegam angustiadas ou desesperadas ao ambulatório, Júlia tenta manter as emoções sob rigoroso controle racional.

Júlia tem 42 anos, também fez um curso superior e trabalha na área comercial. Seu primeiro marido, pai de Júlio e do filho caçula, foi assassinado durante um assalto, quando Júlia estava grávida do segundo filho (já no final da gestação, no oitavo mês) e Júlio tinha dois anos de idade. Na época em que a entrevista foi realizada, vivia em sua casa com seus dois filhos e seu segundo marido. $\mathrm{Na}$ entrevista de dona Leonora, realizada cerca de seis meses após a entrevista com Júlia, a senhora estava morando com o neto, filho caçula de Júlia. As "migrações" dos dois garotos entre os lares da mãe e da avó são consideradas fatos corriqueiros pela família.

Sobre sua história de vida, conta que morava em uma grande cidade com os pais, mas sempre teve desejo de viver em um município menor, em especial a cidade onde hoje reside. Relata o desejo de ter uma trajetória de vida diferente da que teve a mãe. Enquanto uma está satisfeita com a cidade em que vive, a outra está insatisfeita. Tal contrariedade é marcante ao longo da trajetória de vida familiar e perdura até os dias atuais. Júlia conheceu seu marido na cidade em que vive atualmente e lá constituíram família. A participante dá destaque à morte do primeiro marido, descrevendo o fato trágico como desencadeador de um período de muitas dificuldades e sofrimento em sua vida. 
Júlia reforça que sempre foi batalhadora, buscando constantemente vencer as barreiras impostas pela vida. Além do falecimento traumático do primeiro marido, destaca a AN de Júlio como um dos grandes problemas de sua vida. Júlia ficou viúva por cinco anos, quando então conheceu seu segundo marido, iniciaram um relacionamento e estão juntos até hoje.

Júlio era o único paciente do sexo masculino em tratamento no período da coleta de dados. Quando a entrevistadora lhe fez o convite para participar da pesquisa, ele prontamente aceitou. $\mathrm{O}$ adolescente fala pouco, porém em alguns comentários parece "querer impressionar", exibindo um estereótipo masculino agressivo. Parecia guardar alguma dor intensa e sem nome, que deixava a pesquisadora receosa de fazer determinadas perguntas, especialmente as que tratavam de sua família, pois tinha a percepção, nos contatos realizados no serviço, de que se tratava de uma mãe que negligenciava os cuidados com o filho. Além disso, a morte do pai em circunstâncias trágicas parecia ainda trazer considerável sofrimento ao garoto.

$\mathrm{Na}$ época da entrevista, Júlio iniciara o tratamento no serviço havia cerca de dois meses e estava recuperando peso rapidamente, surpreendendo os profissionais da equipe. Inicialmente, contou que morava com sua avó, mas que estava há um mês na casa da mãe, e assim permaneceu. Sobre sua vida, conta que é um garoto alegre, porém quieto. Gosta de ter amigos e de manter atividades fora do lar, como jogar futebol na rua, andar de bicicleta e praticar esportes. Diz que não gosta de ficar em casa em frente do computador ou videogame, como muitos garotos de sua idade.

\section{Fatos marcantes da infância}

Dona Leonora destaca a vida financeiramente tranquila de sua família e a intranquilidade vivenciada na relação com a mãe. O legado que dona Leonora declara ter levado de sua infância é um antigo ditado: “criança não tem que querer". A mãe, muito séria e rígida, dava pouco espaço para os filhos expressarem seus desejos, afetos e seu "lado insatisfeito".

O irmão de dona Leonora tinha uma doença crônica, que ela denominou de reumatismo infeccioso. Ela o descreve como um menino muito tímido e magro, corpo franzino e atarracado, enquanto a senhora se descreve como uma menina "forte e rechonchuda”. Lembra-se que a mãe era muito zelosa do filho, devido à sua fragilidade, o que suscitava sentimentos de ciúme e raiva em dona Leonora. Hoje o filho é mais distante da mãe, vive em outra cidade e dona Leonora participa ativamente da rotina de cuidados da mãe, porém sente que o irmão tem um relacionamento afetivo mais saudável com ela, enquanto ela sente que exercita, por meio desses cuidados, o senso de responsabilidade e obrigação, aliado com o traço de obstinação que aprendeu com sua mãe. Nesse sentido, dona Leonora conta que sempre foi boa aluna, tirava as melhores notas da turma, aprendendo assim a tirar proveito do lado bom da extrema rigidez de uma mãe exigente, que lhe ensinou a ser perfeccionista e persistente.

Júlia, ao recordar sua infância, relembra o condomínio em que a família vivia, onde ela tinha muitos amigos e muitas possibilidades de diversão. Ressalta, ainda, que a mãe era uma pessoa "muito legal, muito aberta”, o que fez de sua infância uma época tranquila de sua vida. Júlia relata que sempre teve bom relacionamento com seus irmãos, mais jovens do que ela. Como irmã mais velha, apreciava mandar nos irmãos, sentia-se "mandona" e brava. Gostava que os garotos agissem cada um à sua maneira, já dando indícios de características de personalidade herdadas das gerações anteriores.

Contrastando com os cenários infantis delineados pela avó e pela mãe, Júlio rememora as perdas trágicas que marcaram sua infância, como o falecimento de seu pai e de seu tio paterno. Conta que o pai foi "assaltado e tomou um tiro" e que seu tio morreu no mesmo ano, em decorrência de complicações de um câncer.

\section{Fatos marcantes da adolescência}

Dona Leonora relata ter vivido sua juventude permeada por brigas com a mãe. Foi uma "adolescência normal", que envolvia estudos, amigos, paqueras, festinhas e clubes. Dona Leonora relata que não teve uma "fase agressiva" na adolescência, pois não havia possibilidade ou abertura para isso naquela época - afinal, o lema que guarda até hoje de sua infância é "criança não tem que querer" -, porém sempre contestava as normas e ordens da mãe, dizendo ter sido uma filha "malcriada", porém respeitosa.

Júlia, assim como acontecera nos relatos da infância, evoca em sua fala uma época tranquila, em que era caseira, não gostava muito de sair de casa. 
Ainda assim, percebia-se como uma adolescente "respondona e malcriada", percepção que coincide com a que sua mãe, dona Leonora, tinha de sua própria adolescência - uma época de contestações, mas mantendo o respeito imposto pelos pais (principalmente pela mãe) dentro do lar. Desde aquela época Júlia já esboçava o desejo de viver em uma cidade menor.

Os relatos de Júlio sobre sua adolescência ficaram centrados na primeira vez em que ingeriu bebidas alcoólicas e em suas tentativas de suicídio, que não apareceram concretamente nos relatos da mãe e da avó. Estas talvez tenham uma percepção diferente dessas tentativas do neto dar fim à própria vida, já que em nenhuma delas Júlio se aproximou do risco de morte. No primeiro episódio ele amarrou um cinto no chuveiro e o objeto foi encontrado pela avó, o que coibiu possível tentativa. Em outro episódio, Júlio ingeriu suco de laranja com álcool etílico, passou mal, mas não teve maiores complicações.

\section{Relacionamento com os pais}

Para dona Leonora, o relacionamento com os pais sempre foi marcado por boa convivência com o pai, percebido como um homem tranquilo e amigável, porém firme, quando necessário, na educação dos filhos. A relação com a mãe foi vivenciada de maneira diferente, talvez no extremo oposto do que foi descrito com o pai. Para Júlia, o relacionamento com os pais era marcado pela forte presença da mãe e ausência afetiva do pai, que sempre fora um bom provedor material da família. Já a mãe possibilitava um relacionamento aberto e próximo, mas mantinha a rigidez nas práticas educativas, aprendida com sua própria mãe, a quem tinha como modelo.

A gente vê aquele pai, o que eu vejo hoje é que na época eu não sentia muita falta, minha mãe supria isso, mas o meu pai nunca foi aquele pai que foi ao shopping para comprar uma roupa, nunca foi aquele pai que foi no zoológico com a gente, aquele pai que levou no cinema, não. O meu pai, ele saía pra trabalhar sempre muito cedo, né, e voltava a noite. Por causa do alcoolismo, ele à noite estava sempre mal humorado, então, assim, não brigava com a gente, mas não tinha um diálogo, né, não tive muita... Compartilhava, mas não era aquele contato assim, de amigo, não (Júlia, mãe, 42 anos).
Confirmando o relato de dona Leonora, Júlia percebe a mãe como uma mulher forte, que ocupara o "lugar vago" deixado pela figura opaca do pai. Assim, o genitor parecia vagar como um fantasma pelo lar, lembrado pelo aspecto financeiro, mas não por ser um pai participativo. A lembrança que Júlio tem do vínculo com o pai é de uma relação forte e intensa, já que ele era sua inspiração. Lembra-se que ele era rígido e controlador com a esposa ("como era antigamente”), porém, cumpriu seu papel de homem da casa, sustentando financeiramente o lar. Relata também ter um bom relacionamento com sua mãe e que sempre foi seu companheiro, mas que também a percebe como uma mulher "brava" e pouco liberal no que diz respeito a autorizar alguns desejos dele, como sair com amigos para participar de grandes eventos.

\section{As vivências do corpo e a alimentação}

Em relação à sua alimentação, Dona Leonora conta que, na época de infância/adolescência, as refeições eram preparadas pela funcionária doméstica, com o auxílio da mãe, que sempre gostava de tudo impecável e "do seu jeito". A mãe também gostava de cozinhar, tornou-se especialista em comida árabe, para agradar o marido, descendente dessa nacionalidade. Relata um episódio em que a mãe, insatisfeita com o preparo de uma carne, bateu um pedaço de bife na cabeça de uma das funcionárias. Havia muita rotatividade de empregadas no lar, pois a mãe sempre brigava com elas. Ao mesmo tempo, dona Leonora conta que a mãe sempre ajudou suas funcionárias, por exemplo, ofertando presentes, pequenos objetos. É possível perceber um intenso movimento do tipo "bate e assopra" da mãe de dona Leonora, possivelmente uma expressão inadequada da agressividade, que parece estar sempre contida e camuflada nos mínimos detalhes dos cuidados concretos com o lar.

Quando dona Leonora casou-se e constituiu sua família, tentou modificar a rotina do lar no modo que havia aprendido, desde a infância, com a mãe. Conta que, atualmente, não tem o hábito de arrumar sua cama. Foge das tarefas domésticas, pois foi algo que precisava fazer diariamente e com perfeição, obrigada pela mãe. Sobre o preparo da alimentação após o casamento, relata não ser sua atividade preferida. Refere que, atualmente, ela, filha e netos almoçam sempre fora de casa, buscando restaurantes que ofereçam refeições rápidas, já que o cotidiano exige que 
voltem logo ao trabalho. Contrária à fala anterior, em que dona Leonora sente que tentou erradicar de sua vida o modelo instaurado pela mãe no que concerne aos cuidados do lar e da alimentação, ela traz a percepção de que muitos desses costumes continuaram arraigados e foram perpetuados em sua família.

Dona Leonora relata que sua filha, Júlia, adora cozinhar e é muito organizada com a limpeza da cozinha. Quando criança, Júlia passava muito tempo com a avó, enquanto ela trabalhava, e aprendeu muito do cuidado com o lar e do preparo de refeições. Percebe que são parecidas nesse aspecto. Porém, destaca que Júlia, ao contrário da avó, é muito "alto astral". Em relação às compras de mantimentos, admite que também não gosta de desempenhar essa atividade, que faz por obrigação. Seu marido sempre foi o responsável por desincumbir-se dessa responsabilidade. Na casa de seus pais, ambos dividiam essa tarefa cotidiana. Nessa época, as refeições eram realizadas em conjunto e "com seriedade".

Hoje em dia não há regras em relação às refeições. Os horários são variados e os locais em que as refeições acontecem também. Dona Leonora almoça com um dos netos e Júlia almoça com o outro. Quando possível, almoçam os quatro juntos. O jantar também acontece nos mesmos moldes. Dona Leonora conta (algo que a pesquisadora pôde, inclusive, observar) que em sua casa não há mesa para as refeições. Ela justifica, mas não lamenta essa falta, dizendo que não havia espaço adequado para isso. Quando comem em casa, sentam-se no sofá. Os netos, algumas vezes, comem na cama, enquanto utilizam o computador. A aversão às refeições realizadas em esquema rígido e sério, com pouca possibilidade de prazer e liberdade, como relatados por ela, parece ter resultado em uma desestruturação e evitação desse momento de comensalidade. Não há espaço (concreto e emocional) para a realização de uma refeição em família, momento que pode oportunizar diálogo e comunicação entre os familiares.

Em relação ao seu próprio corpo, Dona Leonora é muito enfática ao dizer que não está satisfeita "de jeito nenhum". A senhora aumenta seu tom de voz quando a pesquisadora a questiona se ela está satisfeita com seu corpo, respondendo com um longo e agudo "não!". Foi possível perceber que estavam entrando em um campo vulnerável e delicado para ela. A entrevistadora se sentiu "pisando em ovos". Sobre sua insatisfação, relata:
Com tudo! Primeiro eu acho que é por estética mesmo, porque a gente fica feia, certo? [...] Sou muito pesada, eu sou muito ativa e eu acho que, no fim do dia, eu fico muito mais cansada do que as outras pessoas, porque eu tenho a mesma, ou mais atividades do que elas, só que eu carrego um peso muito maior. Me incomoda muito essa coisa de... a hora que agacha, fica difícil de subir por causa da... difícil abaixar por causa da barriga e difícil subir porque o peso é grande para o corpo equilibrar. Porque não é saudável, porque eu me sinto tolhida, principalmente, e isso eu acho superimportante, pra mim, principalmente porque eu sempre fui uma pessoa superesportiva [...]. Eu não sou a gorda que se aceita gorda, não me aceito mesmo e vou morrer sem me aceitar. Não quero nem fazer força pra me aceitar. Eu já deixei de ir em casamentos, em formaturas, em... (Leonora, avó, 68 anos).

Dona Leonora evidencia acentuado desconforto com o próprio corpo e insatisfação com o avanço da idade, sobretudo em relação ao formato e estética do corpo, mas também quanto à perda de agilidade e flexibilidade. Talvez por ter sido avó em uma fase mais jovem, já vivencie a idealização de uma imagem corporal que vêm sendo difundida amplamente há algumas décadas: o corpo magro e jovem, que vem sendo erigido como objeto de desejo e satisfação pelas mulheres de todas as idades (Borges, \& Magalhães, 2011; Vianna, 2003; Withaker, 1988).

Quando o meu marido... o meu marido dava aula em três faculdades, ele fez especialização, ele teve muita... na festa de especialização dele, eu não fui, porque eu estava gorda e não tinha vestido e eu falei: "Eu não vou comprar um vestido gorda”. Então assim, isso é uma coisa que isso daí, eu acho que é um dos meus maiores problemas atualmente, além dessa parte financeira de que eu já te falei, que é superimportante, é... eu acho que o que me incomoda é eu estar gorda agora. [...]. Só que eu não tô conseguindo emagrecer, por conta de tensão, porque eu sou aquela que descarrega, tem um probleminha eu corro na geladeira, então não estou conseguindo. E já não estou conseguindo há alguns anos, viu? Já faz uns, desde que eu vim pra [cidade atual] eu já tava mais gordinha, mais gorda, aí foi piorando e pio- 
rando. Então, não, esse é o meu maior problema, eu acho que agora (Leonora, avó, 68 anos).

A participante relata que, em sua primeira gravidez, ganhara 25 quilos, e que desde então está em permanente luta contra a balança e o formato de seu corpo, em um movimento pendular de aumento e perda de peso ("efeito sanfona"), sem encontrar um equilíbrio entre os extremos. Diz que há quatro anos está obesa. Na percepção - apenas visual - da entrevistadora trata-se de sobrepeso, mas não obesidade. É possível conjecturar se seria um indício de distorção da imagem corporal, ou a evidência de uma insatisfação crônica que se manifesta no plano corporal?

Em relação à alimentação, Júlia conta que ela e os filhos têm o hábito de comer fora durante a semana, já que a "correria" diária não lhe reserva tempo para preparar os alimentos em casa. Aos finais de semana, Júlia gosta de cozinhar para a família e para os amigos, e sempre recebe pessoas em sua casa. Na época da entrevista, o filho Júlio retornara para sua casa havia três semanas. Antes ele morava com a avó. Júlia relata que os horários de refeições em sua casa são "bagunçados" e que não há regras. Antes, ela tomava café da manhã com seu marido. Hoje ela precisa levar Júlio na escola, então não faz essa refeição, alegando não ter tempo.

Sobre as vivências relacionadas ao seu corpo, relata que não está satisfeita. Gostaria de perder peso, ficar mais magra e assim sentir-se mais bonita: "ficar numa forma um pouquinho melhor". Júlia conta que, ao longo da vida, sempre teve problemas com o peso, e que tem esperança de chegar ao padrão que deseja. A equipe de saúde oferece constantes orientações à Júlia para tentar reorganizar a rotina familiar de alimentação, com o propósito de ajudar Júlio, mas ela é muito resistente a essas orientações.

Sobre seu corpo, Júlio se diz insatisfeito, percebe que recuperou peso com o início do tratamento, então as roupas estão mais apertadas, o que lhe deixa muito bravo. Relata ter um "nervosismo" que sempre o acompanha, o que sugere vulnerabilidade emocional, talvez parecida com os momentos de explosão de sua mãe e sua avó. A percepção do corpo em processo de crescimento o deixa fragilizado e emocionalmente instável. É válido ressaltar que Júlio, apesar de sua extrema insatisfação corporal, recuperou o peso perdido em pouco tempo de tratamento, mas sempre ressaltando o desprazer que isso lhe acarre- tava. A recuperação de peso parece ter acontecido de maneira pouco saudável, pois os horários das refeições continuam caóticos, assim como é inadequada a escolha dos alimentos, sempre supercalóricos e de baixo valor nutricional.

Dona Leonora relata que, tanto ela quanto a filha Júlia - que também luta com a balança, desejam ardentemente que Júlio não seja gordo, alegando que ele não se sentiria feliz, pois está melhor com o peso na faixa considerada saudável para sua idade e altura. Reforça que Júlio está conseguindo manter-se no peso adequado, com altos e baixos, e às custas de remédios que controlam sua impulsividade. Conta que antes era intensa a restrição alimentar, que o deixou em estado de grave desnutrição. Relata que o neto ainda não conseguiu equilibrar sua alimentação, assim como ela própria, que tem décadas de luta contra seus impulsos, que se manifestam no comportamento alimentar. Júlio, ao conseguir restringir sua alimentação, inicialmente perdeu alguns quilos. Foi elogiado pela mãe e avó, que repetidas vezes ao longo da vida tentaram também restringir a alimentação, sem obter sucesso, mantendo-se queixosas em relação à gordura corporal.

Apesar de observar a rápida recuperação de peso, dona Leonora ainda se preocupa com Júlio. O neto elegeu como sua imagem preferida uma foto em que estava muito emagrecido.

Porque ele ficou "campo de concentração", era puro osso, não tinha bunda, não tinha nada. Eu falei: "gente, como que a pessoa chega a esse ponto?”, não é? Você enxergava as costelas, as vértebras, é uma pele em cima do esqueleto, né? E não, Deus me livre, eu prefiro ele gordinho e tudo. Mas agora, eu acho que precisa ser um gordinho alegre, né, um gordinho que se aceite. Eu acho difícil, viu, o gordo que se aceita, porque a pressão hoje é tão grande, tudo pressiona: a moda, as atividades, as pessoas, tudo leva você a querer tá magro, não é? E eu acho difícil, mas eu, assim, ver o Júlio gordo de novo eu não queria. Agora, não quero também que ele fique doente, né? Também não quero... (Leonora, avó, 68 anos).

As mensagens sobre corpo e forma física, transmitidas ao adolescente, são confusas e contraditórias. Diz-se que é possível "ser gordo", se isso trouxer felicidade e satisfação. Porém, não parece 
admissível ser "gordo e feliz" em uma família em que a gordura é tomada como repulsiva - um verdadeiro paradigma da feiúra. Os sintomas de Júlio parecem evidenciar esse discurso ambíguo, já que o jovem, em pouco tempo de tratamento, saiu de uma severa e intensa restrição alimentar para uma preocupante manifestação de comportamentos de compulsão alimentar.

\section{Os cuidados maternos percebidos e transmitidos}

Em relação à força do vínculo mãe-filho, envolto por uma aura ambivalente de amor e ódio, percebe-se que dona Leonora tenta conscientemente escapar das heranças psíquicas transmitidas pela mãe. Ao contrário desta, é menos cuidadosa com seu lar e desvaloriza as regras instituídas pela mãe no momento das refeições, que estabeleciam horários, presença obrigatória de todos à mesa e respeito aos mais velhos (dona Leonora nunca comia a última porção de alimento, receando que seus pais também o desejassem, o que sugere uma certa indiferenciação da personalidade, que se expressava no plano da alimentação). Dona Leonora foi muito além de sua mãe: não quis ocupar seu espaço como uma mulher rígida que tinha como parceiro um homem afetuoso - colocou-se nos dois papéis - a mãe séria e brava, mas também amiga e companheira, com um marido pouco percebido no contato emocional. Essa função foi, de certo modo, engolfada por dona Leonora - "mãe e pai" dos filhos do casal.

Em outros aspectos, dona Leonora mantém intenso processo de identificação com a mãe. Ambas deixam-se levar pelas emoções raivosas, são consideradas (e se consideram) mulheres bravas e explosivas. Sempre que possível, vale-se de racionalização para enfrentar as angústias. Dona Leonora relata que, atualmente, cuida de sua mãe (na época da entrevista com 93 anos), porém não parece haver afeto ou emoções envolvidas - é uma relação baseada na obrigação moral, ou seja, a filha deve cuidar da mãe para um dia poder também ser merecedora de receber os cuidados de sua filha. Circulam fantasias na família de que o que é oferecido um dia será devolvido, no que concerne aos cuidados entre mãe e filha. Os homens (filhos) são vistos como afetivos e cuidadosos, porém inábeis para sustentarem o contato concreto, capacidade que é atribuída às mulheres.
Dona Leonora confidencia que, após muitos anos de se submeter à análise freudiana (sic), tem plena consciência de alguns "erros e acertos" que cometeu na educação dos filhos.

Eu acho que eu repeti com eles muito das coisas que eu odiei a mamãe ter feito comigo, mesmo que objetivamente eu soubesse que eu não podia fazer aquilo. Eu não sou uma pessoa ignorante, fiz faculdade, tive aula, tive psicologia, tive formação universitária, li quinhentos mil livros, literatura, então você tem uma visão grande da vida, do ser humano, você não consegue ficar fechada ali naquele mundinho [...] Então acho que é mais um motivo pra eu me cobrar: "poxa, você sabia tanto, você sabia que você não gostava de como você foi tratada, você sabia o que é certo, então por que você não faz?". Mas é engraçado como é forjado o temperamento, né? O meu temperamento foi forjado assim, da educação que eu tive da minha mãe, e por isso que eu procurei psicólogo, por isso que eu procurei analista, porque eu tinha consciência de que sozinha a gente não vence isso, não é? Como a gente não vence mesmo. Então eu acho que eu podia, tipo, eu enxergo bem que eu, o que eu não gosto da Júlia é que, às vezes, ela é explosiva, às vezes, ela grita, tá repetindo a história, entendeu? Então assim, eu tenho, eu não consigo ver a vida dos meus filhos só: “ah, eles são assim", eu sempre que eu vejo eu penso: "Poxa, poderia ser diferente se eu tivesse sido diferente também (Leonora, avó, 68 anos).

Indagada sobre como percebe a filha no exercício da maternagem, dona Leonora responde que a vê como uma boa mãe, porém acha que Júlia carregou algumas características suas (que ela, por sua vez, diz ter carregado de sua mãe), que ela considera negativas, como ser explosiva e a inquietação, a falta de tranquilidade. Percebe que a filha se esforça para cuidar dos filhos, mas nem sempre consegue ser uma mãe carinhosa: "Vamos dizer que ela é bem assim, $80 \%$... é uma boa mãe". A senhora relata que Júlia tem uma característica que ela admira, mas, ao mesmo tempo, questiona, no cuidado com os filhos. Diz que Júlia, há cerca de sete anos em um novo relacionamento, tem seus momentos de cuidar dos filhos, mas também o momento em que os deixa em segundo plano, para curtir a vida com o marido. Dona Leonora sente que 
não se formou uma nova família com a chegada do companheiro de Júlia, apenas um novo casamento, em que o marido de Júlia não abraçou os garotos como parte da família.

É possível perceber que Júlia é uma mãe explosiva, como sua mãe também se descreveu. Porém, diferentemente de dona Leonora, não ocupou o espaço deixado vago pelo marido na família. Talvez a perda concreta e prematura de seu companheiro tenha lhe impelido a se ausentar desse contato emocional, já que teve, sem ter consciência clara desse desejo, que ocupar as duas funções. Assim, a avó ocupou esse lugar de "pai" dos garotos, mas também usurpou ou se apropriou parcialmente da função de mãe, "autorizada" por sua filha.

Júlia sente que não consegue retribuir à mãe o carinho e ajuda que ela lhe oferece. Diz-se muito dependente de dona Leonora e carente de seus cuidados. A senhora divide com as filhas as tarefas relacionadas à maternagem, o que também abre espaço para que Júlia "seja feliz sozinha com seu marido", como é de seu desejo.

Júlio diz que a mãe lhe dá muitos conselhos, mas não relata experiências de envolvimento emocional. Em outra via, vê-se como um filho rebelde (rebelando-se frente à falta de atenção?), mas "legal". Suas rebeldias podem ser percebidas, segundo ele, em seu desejo de começar a ingerir bebidas alcoólicas (lembrando que seu avô paterno faleceu em decorrência do alcoolismo, na época em que Júlio iniciou os sintomas de AN), em suas tentativas de se cortar, e no seu humor instável, pois sempre está "muito nervoso".

\section{Transmissão da feminilidade}

No plano da identificação com o feminino, Dona Leonora, mesmo conscientemente insatisfeita, parece ter se identificado com vários aspectos de sua mãe. Há evidências de uma tentativa de reparação (percebida na repetição do padrão de vinculação) da relação com a filha Júlia. Agora, já adulta e mais madura, dona Leonora cuida da mãe idosa, porém sem conseguir estabelecer um contato genuinamente afetivo - coloca-se na obrigação de cuidar da mãe (formação reativa), possivelmente em uma tentativa de restaurar o afeto perdido, que pode ter se transformado em ódio. Os sentimentos ambivalentes (amor e ódio) entre mãe e filha podem sugerir uma tentativa de diferenciação entre as duas (Ribeiro, 2011), o que parece ainda não ter sido alcançado pelas mulheres da Família Miranda. As mães parecem exigentes e cruéis, ao mesmo tempo em que há necessidade (e busca incessante) de contato afetivo entre mãe e filha. Para Ribeiro (2011), se não há um encontro minimamente satisfatório entre mãe e filha, é sinal de que pode haver precariedade e desorganização da feminilidade.

Dona Leonora afirma que, principalmente na época atual, em que se sente mais madura, dedica-se mais aos filhos, esperando receber futuramente os cuidados em troca, quando necessário. A mudança de cidade aconteceu para ajudar a filha no cuidado com seus filhos, mas também esperando que esta retribua esse cuidado, quando a senhora não for mais independente e capaz de suprir seu autocuidado.

A transmissão da feminilidade ocorre com maior intensidade em linhagens de mulheres, mas não apenas. Os garotos também são influenciados e identificam-se com a figura materna (Ribeiro, 2011). Júlio evidencia estar intensamente identificado às insatisfações corporais de mãe e avó, que por sua vez estão associadas a emoções explosivas. Assim, Júlia the transmitiu, como principal via de identificação, seu próprio nome. Júlio diz que não sabe como seu nome foi escolhido, mas sabe dizer quem o escolheu: a mãe. Diferentemente do que aparece no relato de Júlia, diz que o pai não queria esse nome, mas o aceitou por insistência da mãe.

Dona Leonora e Júlia desejavam uma filha, talvez em uma tentativa de poderem reparar suas próprias relações com a figura materna. Júlia não conseguiu concretizar esse desejo, teve dois filhos e colocou no primeiro a versão masculina de seu nome. Parece ter acontecido um estreitamento do relacionamento entre mãe e filho, especialmente após a morte do pai. Após o segundo casamento de Júlia, talvez se possa pensar em uma tentativa forçada de desidentificação, em que Júlia se voltou totalmente para o marido, e Júlio se ausentou do contato diário no lar. Sem uma elaboração satisfatória dessa vivência de separação, Júlio desenvolveu um sintoma, identificando-se com as dificuldades da mãe - e da avó - no que concerne à má integração da imagem corporal e profunda insatisfação com a forma e o peso corporal.

O primeiro objeto de identificação da criança é a mãe. Para a menina, este seria um fator de segurança, já que sua feminilidade estaria protegida. Já o garoto pode ter sua masculinidade ameaçada, a depender da perda da identificação com a mãe e 
da identificação posterior com o pai. Para Ribeiro (2011), a identificação com o pai é menos problemática, na medida em que há um distanciamento parcial, enquanto que a relação mãe-bebê depende de fusão e depois de separação - que nunca é alcançada totalmente no curso da vida. Júlio perdeu o pai ainda muito pequeno e seu contato afetivo mais duradouro foi com a mãe e avó materna. Avó, mãe e neto parecem se encontrar no temor pela gordura e nas dificuldades em controlar os impulsos, que se manifesta de forma deslocada na alimentação. Em uma família em que as mães desejam filhas, Júlio se identificou com tais características, e parece se sentir mais próximo e aceito por essas mulheres exigentes. O segredo familiar se inicia aí. Dona Leonora e Júlia evitam comentar diante do adolescente suas insatisfações corporais. Assim, a família se estrutura precariamente sobre a base de um esquema alimentar confuso e da insegurança quanto ao real espaço que cabe aos filhos frente às necessidades afetivas dos pais. Esse desconforto não claramente nomeado acaba sendo denunciado, indiretamente, pelo jovem ao manifestar sintomas graves de um TA.

\section{Anorexia nervosa}

Dona Leonora mostra-se ambivalente em relação à AN. Diz que não gostaria que o neto estivesse doente, mas deseja que ele seja magro, para evitar os desprazeres que ela credita como próprios às pessoas com sobrepeso. A senhora relata que os sintomas iniciaram-se próximo à morte do avô. $\mathrm{O}$ garoto se mostrava muito preocupado e curioso com a possibilidade de morte do avô, que seguia internado na UTI, manifestando o desejo de visita-lo todos os dias. Parece ter havido uma forte identificação entre neto e avô nesse período de perda iminente, sendo possível considerar que o avô era o referencial masculino de Júlio, que perdera o pai aos dois anos de idade.

Dona Leonora sente que seu neto mais jovem, irmão de Júlio, identificou-se com o marido de Júlia, talvez por não ter conhecido seu pai (estava no útero quando o pai faleceu). Assim, Júlio perdeu o espaço que tinha em casa, pois não contava com a atenção da mãe, que estava mais voltada para o início do casamento. Júlio, então, esboçou o desejo de viver com a avó, em seu apartamento. A avó sente que a AN ajudou Júlio a reaproximar-se da mãe, que durante o tratamento pôde resgatar os cuidados para com ele.
Dona Leonora percebe que agora Júlio trava uma batalha, que segundo ela será vivida até o fim da vida, no que diz respeito à alimentação. Ela admite que vive na própria pele essa batalha, já que está sempre em guerra com seu corpo, com a balança e com os sinais do avanço da idade. Relata que Júlio, quando criança, já foi "obesinho", mas que teve um problema estomacal e uma pequena perda de peso por esse motivo, já que os alimentos não lhe caíam bem. A família buscou o tratamento adequado, mas dona Leonora acha que o neto experimentou ficar mais magro, gostou, foi elogiado e acabou perdendo o controle, passando a restringir muito a alimentação, ao mesmo tempo em que iniciou a prática intensa de exercícios físicos.

A percepção atual que dona Leonora tem da AN é a de que se trata de um problema sério e que exige tratamento intensivo. Ela acha que, por ser uma "doença psicológica", é de difícil (ou impossível) cura, pois "faz parte da personalidade". A experiência de dona Leonora lhe mostra que esse sofrimento é de difícil erradicação, já que ela própria vivencia esse temor exagerado da gordura e da degradação física acarretada pelo envelhecimento, sugerindo que é possível aprender a viver melhor com alguns aspectos, mas que eles não se evadem da personalidade.

Júlia percebe seu filho como um garoto feliz e alegre, mas com o desenvolvimento da AN, essa percepção foi modificada. A psicopatologia parece ter sido a maneira inconsciente e muda do garoto requisitar o olhar da mãe. Ela, agora, o vê como um garoto triste e dependente de seus cuidados, que anteriormente ela havia delegado à sua mãe. Ainda no início do tratamento, apresenta uma compreensão superficial da problemática do filho, pensando que a "mágica" recuperação do peso equivalia à cura.

Sobre mudanças na rotina familiar após o início dos sintomas do filho, Júlia relata, surpreendentemente, que não houve modificações. Aponta diferenças apenas no seu olhar e na atenção dada ao adolescente.

Era normal como é hoje, mas, por exemplo, em relação ao Júlio, ao transtorno alimentar com ele, às vezes eu deixava ele, deixei de prestar atenção em muitas coisas do Júlio, então, às vezes, assim, deixei de achar que... achava que ele era independente e deixei de ter um olhar assim mais atento. Hoje eu tô resgatando o Júlio, acho que já resgatei. Não só com o Júlio, porque assim, antes chegava final de semana e eu queria sair, eu que- 
ria passear e eu o deixei um pouco, né, de lado, eu via muito o meu lado. Hoje eu pondero um pouco mais, tenho um olhar de novo para resgatar aquele lado família (Júlia, mãe, 42 anos).

Júlia relata que, após o início do seu segundo casamento, ficou mais atenta ao marido e às atividades de lazer que gostaria de compartilhar com ele (viagens, festas e passeios com os amigos), reduzindo a atenção dada aos filhos, especialmente Júlio, que saiu concretamente de seu campo de visão ao se mudar para a casa da avó. Demorou a perceber que o filho estava com sintomas de $\mathrm{AN}$, pois estava pouco atenta à sua alimentação, considerando normais suas escolhas alimentares. Também não percebia a intensa atividade física a que o garoto se dedicava ao longo do dia.

Júlio, no que concerne à AN, diz que pouco sabia sobre o tema antes de receber o diagnóstico. Conta que havia feito um trabalho sobre o tema para a escola, porém se envolvera superficialmente. Diz que não enxergou que estava doente no início dos sintomas e que quem percebeu foi sua mãe. Além de restringir a alimentação, ficou mais triste, não conseguia interagir com os colegas de escola e fechou-se em seu universo próprio. Hoje sente que é muito cobrado por seus familiares, que estão atentos a ele. Percebe que a AN "não tem meio termo", o que parece ser característico de seus sintomas: restrição intensa da alimentação, no início do quadro, e manifestação de comportamentos compulsivos, atualmente.

Após a morte do avô, os sintomas se intensificaram. A restrição alimentar ocupava seus pensamentos e suas emoções - "emagrecer e ficar mais bonito" - como aprendeu que deve ser, para ser aceito na Família Miranda. Isso pode ser ilustrado com a máxima de dona Leonora: "eu não acho que tem algum gordo que se aceite". Júlio repete a luta diária de sua mãe e de sua avó, uma guerra contra o corpo, que não se deixa dobrar pela tentativa de controle mental, uma batalha que se estende contra seus impulsos e desejos. Percebe-se que as emoções "explodem" nos três membros da Família Miranda, com manifestações de raiva, ódio e rejeição que são canalizadas para a relação com o alimento, na qual encontram uma válvula de escape. As experiências alegres são percebidas nas entrelinhas, porém também estas trazem tristezas. Quando Júlia se diverte, reforçando sua aliança junto ao marido e amigos, avó e filho sentem-se abandonados. Os vínculos mostram-se frágeis, já que é possível perdê-los a qualquer momento (Eiguer, 1985) e sem qualquer aviso prévio, tal como receber a notícia de um pai assassinado.

Com o desenvolvimento dos sintomas de AN, Júlio parece estar reconquistando os cuidados maternos. A doença aproximou os membros da Família Miranda, na medida em que foram resgatados os cuidados concretos (morar na mesma casa, fazer uma refeição acompanhado) e a esperança de que os cuidados dos aspectos afetivos, imprescindíveis para o fortalecimento do vínculo mãe-filho, também possam florescer.

\section{Considerações finais}

É possível observar na Família Miranda intensas fantasias de abandono e desamparo, sejam elas causadas pela morte concreta de um ente querido, ou ainda na ausência de um contato cotidiano caloroso e acolhedor. Essas fantasias apontam para a existência de um mundo interno esvaziado de sentimentos amorosos. É um cenário familiar ocupado por mulheres fortes, em que os homens têm pouca relevância e possibilidade de protagonismo, pois estão sempre em segundo plano. Essa característica - incidência do pai como uma figura frágil e diáfana, já amplamente conhecida no campo da AN, se repete nas duas gerações (avó e mãe).

De acordo com Ribeiro (2011), o olhar falho da mãe pode ocasionar na criança desprezo em relação a si mesma, pois prevalece a sensação de não poder ser verdadeiramente amada. Dona Leonora e Júlia casaram-se com homens emocionalmente distantes, frios no contato com a esposa e os filhos. As brigas conjugais permearam as duas gerações. Porém, Júlia destaca que seu pai foi um provedor financeiro muito eficaz, enquanto seu primeiro marido era considerado avarento e o segundo companheiro não auxilia na manutenção da casa, pois, conforme as palavras de dona Leonora: "a casa é dos meninos e da Júlia, e o namorado dela mora lá também”. Aparentemente não aconteceu a integração de uma nova família, em termos orgânicos. O sentimento de pertença (Eiguer, 1985) de Júlio pode estar fragilizado. Naquela família não havia espaço subjetivo para o adolescente que se desenvolvia e se reconfigurava, e ele passou a não mais se reconhecer naquele "corpo familiar" que foi totalmente modificado pelo ingresso de um novo membro (Eiguer, 1985; Lisboa, \& Féres-Carneiro, 2005), que, 
além de lhe "roubar" o amor materno, identificou-se claramente com seu irmão (que não conhecera o pai e recebeu melhor o novo marido da mãe nessa função). Restava a Júlio a dor da solidão e do desamparo. Morar com a avó pareceu ser uma boa alternativa para encontrar um lugar que fosse propriamente seu, tanto do ponto de vista concreto como emocional.

Além disso, é possível perceber a repetição do "sintoma" da AN, considerando que avó e mãe apresentam preocupações em relação à forma corporal e lidam com a alimentação de maneira desorganizada e impulsiva. O sintoma anoréxico de Júlio se perpetua com preocupante gravidade (tacitamente negada pela mãe), apontando para a família o padrão conflituoso em que vivem, não apenas no que concerne ao corpo/alimento, mas também no âmbito das emoções e relacionamentos afetivos.
Como afirma a teoria da transmissão psíquica transgeracional, a constituição subjetiva de um indivíduo está invariavelmente envolvida com os objetos, modelos identificatórios, antagonistas ou auxiliares. Assim, com Freud (1921/1980) pode-se afirmar que, desde o princípio, a psicologia individual é também psicologia social.

O presente estudo mostrou que o conhecimento dos mecanismos de transmissão psíquica é um recurso valioso para subsidiar o tratamento da AN, pois pode auxiliar no desvelamento dos segredos familiares que bloqueiam o desenvolvimento da família e de seus membros. Assim, ao encontrar sentido e significado para o sintoma inconsciente na cadeia de transmissão psíquica intergeracional, é possível auxiliar de forma mais efetiva paciente e familiares que se encontram em situação de intenso sofrimento.

\section{Referências}

American Psychiatric Association (2013). Diagnostic and statistical manual of eating disorders (5th ed.). Arlington: o autor.

Andrade,T.F., \&Santos, M.A. (2009). A experiênciacorporal de umadolescentecom transtorno alimentar. RevistaLatinoamericana de Psicopatologia Fundamental, 12(3), 454-468. https:// doi.org/10.1590/S1415-47142009000300003

Appolinário J. C., \& Claudino, A. M. (2000). Transtornos alimentares. Revista Brasileirade Psiquiatria,22(supl2), 28-31. https:// doi.org/10.1590/S1516-44462000000600008

Ávila, L. A. (2004). Grupo e corpo, no enfoque do modelo de Cambridge. Vínculo, 1(1), 23-29. Recuperado de http://pepsic.bvsalud.org/scielo.php?pid=S1806-24902004000100005\&script=sci_abstract

Benghozi, P. (2010). Malhagem, filiação e afiliação: psicanálise dos vínculos: casal, família, grupo, instituição e campo social. (E. D. Galery, Trad.). São Paulo, SP: Vetor.

Bighetti, F., Santos, M. A., Ribeiro, R. P. P., Oliveira, E. A., Unamuno, M. R. L., \& Santos, J. E. (2007). Transtornos alimentares: anorexia e bulimia nervosas. In: C. E. Kalinowski (Org.), PROENF, Programas de atualização em enfermagem, saúde do adulto: Ciclo 2, Módulo 2 (pp. 9-44). Porto Alegre, RS: Artmed.

Borges, C. C., \& Magalhães, A. S. (2011). Laços intergeracionais no contexto contemporâneo. Estudos de Psicologia (Natal), 16(2), 171-177.https://doi.org/10.1590/S1413-294X2011000200008

Braun, V., \& Clarke, V. (2006). Using thematic analysis in psychology. Qualitative Research in Psychology, 3(2), 77-101. https://doi.org/10:1191/1478088706qp063oa

Cartwright, M. M. (2004). Eating disorder emergencies: understanding the medical complexities of the hospitalized eating disordered patient. Critical Care Nursing Clinics of North America, 16(4), 515-530. https:// doi.org/10.1016/j.ccell.2004.07.002

Claudino, A. M., \& Borges, M. B. F. (2002). Critérios diagnósticos para os transtornos alimentares: conceitos em evolução. Revista Brasileira de Psiquiatria, 24(supl 3), 7-12. https://doi.org/10.1590/S1516-44462002000700003

Del Priore, M. (2000). Corpo a corpo com a mulher: Pequena história das transformações do corpo feminino no Brasil. São Paulo, SP: Senac.

Eiguer, A. (1985). Um divã para a família (L. M. V. Fisher, Trad.). Porto Alegre, RS: Artes Médicas.

Eiguer, A. (1998). A transmissão do psiquismo entre gerações (L. H. S. Barbosa, Trad.). São Paulo, SP: Unimarco. 
Fernandes, M. H. (2006). Transtornos alimentares: anorexia e bulimia. São Paulo, SP: Casa do Psicólogo.

Freud, S. (1980). Psicologia de grupo e análise do ego. In S. Freud, Edição standard brasileira das obras psicológicas completas de Sigmund Freud (J. Salomão, Trad., Vol. 18, pp. 89-179). Rio de Janeiro, RJ: Imago. (Original publicado em 1921)

Giddens, A. (2003). Mundo em descontrole: o que a globalização está fazendo de nós (3a ed., M. L. X. A. Borges, Trad.). Rio de Janeiro, RJ: Record.

Gomes, I. C., \& Zanetti, S. A. S. (2009). Transmissão psíquica transgeracional e construção de subjetividade: relato de uma psicoterapia psicanalítica vincular. Psicologia USP, 20(1), 93-108. https://doi.org/10.1590/S0103-65642009000100006

Hoogland, R. (2002). Fact and fantasy: the body of desire in the age of posthumanism. Journal of Gender Studies, 11(3), 213-231. https://doi.org/10.1080/0958923022000021296

Leonidas, C., \& Santos, M. A. (2013). Instrumentos de avaliação da imagem corporal e dos hábitos alimentares na anorexia nervosa: análise da produção científica. Psicologia: Ciência e Profissão, 33(4), 868-883. https://doi.org/10.1590/S1414-98932013000400008

Lisboa, A. V., \& Féres-Carneiro, T. (2005). Quando o adoecimento assombra o grupo familiar. Pulsional: Revista de Psicanálise, 18(184), 40-48.

Mendonça, L. B. V. G. (2015). Adolescência e anorexia: o que entra na pele. In M. Ramos, \& M. P. Fuks (Orgs.), Atendimento psicanalítico da anorexia e bulimia (p. 14-27). São Paulo, SP: Zagodoni.

Oliveira, E. A., \& Santos, M. A. (2006). Perfil psicológico de pacientes com anorexia e bulimia nervosas: a ótica do psicodiagnóstico. Medicina (Ribeirão Preto), 39(3), 353-360. https://doi.org/10.11606/issn.2176-7262.v39i3p353-360

Polivy, J., \& Herman, C. (2002). Causes of eating disorders. Annual Review of Psychology, 53, 187-213. https://doi.org/10.1146/annurev.psych.53.100901.135103

Ribeiro, M. F. R. (2011). De mãe em filha: a transmissão da feminilidade. São Paulo, SP: Escuta.

Roudinesco, E. (2003). A família em desordem (A. Telles, Trad.). Rio de Janeiro, RJ: Jorge Zahar.

Saikali, C. J., Soubhia, C. S., Scalfaro, B. M., \& Cordas, T. A. (2004). Imagem corporal nos transtornos alimentares. Revista de Psiquiatria Clínica, 31(4), 164-166. https:// doi.org/10.1590/S0101-60832004000400006

Stake, R. E. (2000). Case studies. In N. K. Denzin, \& Y. S. Lincoln (Orgs.), Handbook of qualitative research (pp. 435-454). London: Sage.

Valdanha, E. D., Scorsolini-Comin, F., \& Santos, M. A. (2013). Anorexia nervosa e transmissão psíquica transgeracional. Revista Latinoamericana de Psicopatologia Fundamental, 16(1), 71-88. https://doi.org/10.1590/S1415-47142013000100006

Vianna, H. (2003). Introdução. In H. Vianna (Org.), Galeras cariocas: territórios de conflitos e encontros culturais. Rio de Janeiro, RJ: EDUFRJ.

Withaker, D. (1988). Mulher e homem: O mito da desigualdade. São Paulo, SP: Moderna.

\section{Élide Dezoti Valdanha-Ornelas}

Doutoranda em Psicologia pela Universidade de São Paulo, São Paulo - SP, Brasil e pela École Doctorale Recherches en Psychanalyse et Psychopathologie da Université Paris-Diderot (Paris VII), França. Bolsista CAPES e FAPESP (Processo no 2014/18615-4).

E-mail: elide_dezoti@hotmail.coms

\section{Manoel Antônio dos Santos}

Livre-Docente em Psicoterapia Psicanalítica pela Universidade de São Paulo, Ribeirão Preto-SP. Professor Associado 3 do Programa de Pós-Graduação em Psicologia da Faculdade de Filosofia, Ciências e Letras de Ribeirão Preto, Universidade de São Paulo, Ribeirão Preto - SP. Brasil.

E-mail: masantos@ffclrp.usp.br 
Endereço para envio de correspondência:

Faculdade de Filosofia, Ciências e Letras de Ribeirão Preto da Universidade de São Paulo - FFCLRP-USP. Laboratório de Ensino e Pesquisa em Psicologia da Saúde - LEPPS (FFCLRP-USP-CNPq).

Avenida Bandeirantes, 3900. Monte Alegre. CEP: 14040-901.

Ribeirão Preto - SP. Brasil.

Recebido 04/09/2015

Aprovado 14/12/2016

Received 09/04/2015

Approved 12/14/2016

Recibido 04/09/2015

Aceptado 14/12/2016

Como citar:Valdanha-Ornellas, E. D., \& Santos, M. A. (2017). Transtorno alimentar e transmissão psíquica transgeracional em um adolescente do sexo masculino. Psicologia: Ciência e Profissão, 37(1), 176-191. https://doi.org/10.1590/1982-370300287-15

How to cite:Valdanha-Ornellas, E. D., \& Santos, M. A. (2017). Eating disorders and transgenerational psychic transmission in a male teenager. Psicologia:Ciênciae Profissão,37(1), 176-191.https://doi.org/10.1590/1982-370300287-15

Cómo citar:Valdanha-Ornellas, E. D., \& Santos, M. A. (2017). Trastorno alimentar y transmisión psíquica transgeneracional en un adolescente del sexo masculino. Psicologia: Ciência e Profissão, 37(1), 176-191. https://doi.org/10.1590/1982-370300287-15 